\title{
Impacto do MGME na prática pedagógica de professores \\ da rede estadual paulista
}

\author{
Patricia Aparecida Bioto Cavalcanti ${ }^{1}$ \\ Sidney Cabral Lourenço ${ }^{2}$
}

\section{Resumo}

Este texto discute o impacto pós-curso do 'Melhor Gestão, Melhor Ensino' (MGME), Formação de Professores de Ciências em sala de aula. Analisa-se como os professores ex-cursistas estão aplicando as metodologias de ensino trabalhadas no curso de formação. Verifica-se, por meio de entrevistas semiestruturadas, as possíveis elaborações que os professores executaram sobre suas práticas pós MGME e como entendem a formação continuada em suas carreiras e como prática da Secretaria Estadual de Educação de São Paulo. Como resultados, segundo as falas dos professores, apontam-se a positividade das propostas do curso na prática pedagógica do docente bem como a percepção por parte desses professores da importância do MGME em seu percurso profissional e formativo.

Palavras-chave: Melhor Gestão, Melhor Ensino. Formação continuada de professores. Estado docente.

\begin{abstract}
This paper discusses the post-course impact of Better Management, Better Teaching (MGME) Teacher Education in the classroom. It is analyzed how the former teachers are applying the teaching methodologies worked on in the training course. Through semi-structured interviews, the possible elaborations that the teachers performed on their practices after MGME and how they understand the continued formation in their careers and as practice of the State Secretariat of Education of São Paulo, are verified through semi-structured interviews. As a result, according to the teachers' statements, the positivism of the course proposals in the pedagogical practice of the teacher is pointed out, as well as their perception of the importance of MGME in its professional and formative course.
\end{abstract}

Keywords: Better Management. Better Teaching. Continuing education of teachers. Teaching state.

\footnotetext{
${ }^{1}$ Pedagoga. Doutora em Educação pela PUC-SP. Docente da UNINOVE, PROGEPE e Pedagogia. Estuda formaçãao de professores, currículo e história da profissão docente. E-mail: patcavalcanti1@gmail.com

${ }^{2}$ Biólogo. Mestre em Educação pela UNINOVE-PROGEPE. Gestor da rede publica de ensino do Estado de São Paulo. E-mail: sidcalo@hotmail.com
} 


\section{Introdução}

Este texto discute o impacto pós-curso do Melhor Gestão, Melhor Ensino (MGME) Formação de Professores de Ciências em sala de aula. Analisa-se como os professores ex-cursistas estão aplicando as metodologias de ensino trabalhadas no curso de formaçáo. Verifica-se, por meio de entrevistas semiestruturadas, as possíveis elaboraçóes que os professores executaram sobre suas práticas pós MGME e como entendem a formação continuada em suas carreiras e como prática da Secretaria Estadual de Educação de São Paulo.

O estudo insere-se numa perspectiva maior que busca compreender como as políticas educacionais, através de cursos de aperfeiçoamento (formação continuada) pela Secretaria da Educação do Estado de São Paulo, têm influenciado na prática dos professores.

Num primeiro momento o artigo ocupar-se-á em apresentar os cursos que compuseram o MGEME Formação de professores de Ciências em seus três módulos. Trata-se de contribuição inédita sobre os cursos. $\mathrm{O}$ texto foi redigido tomando por base documentos oficiais e a experiência de um dos autores deste texto, que foi consultor do curso e cursista. Há informaçóes detalhadas sobre as datas, composição dos encontros, dinâmicas formativas etc. $\mathrm{O}$ material completo a este respeito, bem como demais discussóes podem ser contempladas na consulta à dissertação de mestrado que deu origem a este artigo.

O universo da pesquisa é composto por dois professores de uma única escola pública paulista localizada na cidade de Sáo Paulo, que realizaram o referido curso. A pesquisa foi de cunho qualitativo. Foi feito o levantamento bibliográfico sobre o tema, que ofereceu os recursos teóricos para análise do material. Documentos oficiais e dispositivos legais também foram levantados e utilizados. Como instrumento de coleta de dados optou-se por um questionário de sondagem e por entrevista semiestruturada.

Como resultados, segundo as falas dos professores, apontam-se a positividade das propostas do curso na prática pedagógica do docente bem como a percepção por parte destes da importância do MGME em seu percurso profissional e formativo.

\section{MGME: concepção}

O Curso Melhor Gestão, Melhor Ensino (MGME) foi instituído pela Resolução SE-22 de 18 de abril de 2013, da Secretaria de Educação de São Paulo (SEESP). Seu objetivo principal era incentivar a formação continuada educadores da rede estadual de ensino, assegurando-lhes atualizaçáo e aperfeiçoamento e, consequentemente, melhor desempenho profissional.

Sua proposta vem na esteira do que foi postulado pelo programa Educação Compromisso de São Paulo, instituído pelo Decreto no 57.571, de 2 de dezembro de 2011, cuja implementação prevê o desenvolvimento de ações que visam à melhoria da educação básica paulista. Dentre as cinco metas deste Programa, as meta 1 e 2 estão relacionadas ao MGME. A primeira diz da necessidade de valorizar e investir no desenvolvimento do capital humano da SEESP, e a segunda do aprimoramento das açôes de gestão pedagógica com foco no resultado dos alunos.

As políticas educacionais do Estado, levadas a efeito há pelo menos duas décadas, estão atreladas aos resultados das avaliaçōes educacionais em rede, como o SARESP e o SAEB. A elaboração do MGME ba- 
seou-se, em muito, nos resultados do SARESP/2012 de Língua Portuguesa, Matemática e Ciências, analisados pelos Professores Coordenadores de Núcleo Pedagógico (PCNP) das Diretorias de Ensino, técnicos da SEESP e equipe de consultores. Foram também considerados os resultados das orientaçóes técnicas realizadas periodicamente em cada diretoria pelos professores e coordenadores das áreas citadas. Considerou-se, ainda, a necessidade de ações de formação e de gestáo do conhecimento que contribuíssem para a consolidação do currículo oficial do Estado de São Paulo.

O MGME inclui-se nas ações de formação continuada dos professores da SEESP que vem acontecendo há pelo menos 15 anos efetivamente. Tais ações passaram a fazer parte do rol de atividades da SEESP pós LDB de 1996, apresentando-se em um grande número de cursos e formaçôes. Apenas sob a tutela da Escola de Formação de Professores Paulo Renato de Souza (EFAP), de 2010 a 2014, 142 cursos foram realizados, segundo pesquisa de Bioto-Cavalcanti (2015).

Afirma a autora que em açóes como a do PEC, Teia do Saber, Rede do Saber e outros tantos programas de formação de professores da SEESP, pelos parâmetros de elaboração e de execução da Proposta Curricular, o Estado de São Paulo vem se configurando como um Estado docente de seus próprios docentes.

O Estado de São Paulo passou a controlar modelos de formação, saberes pedagógicos e políticos de seus professores, formas de estabelecer relaçóes entre os membros da escola e desta com as comunidades, definindo desta forma um estatuto e uma identidade docente comum aos professores da rede pública paulista. Para tanto se utiliza de projetos de formação, de produção e circulação de materiais e documentos em forma articulada às políticas educacionais estaduais (BIOTO-CAVALCANTI, 2015, p.3).

O curso configurou-se segundo a SEESP (2013, p. 8) como um projeto diferenciado e inovador, pois: (1) se apresentou como um modelo de formação continuada em larga escala, ou seja, ele tinha a intenção de atingir "todos" os professores de Língua Portuguesa, Matemática, Ciências, História, Geografia, Educação Física, Artes e Inglês do ensino fundamental séries finais de toda rede estadual e não apenas alguns que se inscrevessem no curso ou que fossem indicados pelas escolas e diretorias de ensino; totalizando 63 mil educadores; (2) a formação se daria, e se deu, durante o horário de trabalho do professor, sem prejuízo financeiro; (3) além da formação a distância, estavam previstos, e ocorreram, encontros presenciais descentralizados por diretoria de ensino, nos quais os professores trocariam suas experiências e produçóes no curso; (4) o curso foi validado por uma equipe de professores da rede, depois de ter tido uma primeira elaboração pelos consultores e técnicos da SEESP, tal validaçáo deu origem ao modelo de curso ofertado, que foi um refazer do projeto original.

\section{MIGME / Ciências: implementação}

O MGME foi planejado para acontecer em três momentos: Curso 1, Formação de Formadores, para 350 PCNPs de Ciências; Curso 2, Formação de professores de Ciências e o Curso 3: Aprofundamento de Conteúdos e Metodologias, para 13.000 Professores de Ciências. Totalizando 13.350 cursistas. 


\section{Curso 1 - Formação de Formadores}

Após a equipe responsável pela elaboração do curso chegar a seu formato definitivo, teve início o Curso 1. O primeiro momento do curso foi um encontro em Serra Negra, que aconteceu de 12 a 14 de agosto de 2013. Neste encontro foi apresentado para supervisores de ensino e PCNPs o curso em si.

Aconteceram também oficinas que faziam parte do curso como um todo e que se deveriam ser replicadas aos professores que fizessem o Curso 2. Estas oficinas tiveram um caráter duplamente formativo para estes PCNPs: os formaram como formadores, que por sua vez, seriam instrumento de formação para os professores cursistas no Curso 2. As oficinas foram divididas 3 temas: 1, Ensino por investigação; 2, Situação de aprendizagem (SA) e seus elementos norteadores, e 3, Perspectivas de avaliação na SA.

Além das oficinas, ocorreram palestras de estudiosos da área, bem como de pessoal da SEESP com vistas a difundir o ideário e o objetivo de formação do MGME, das demais ações formativas da Secretaria e do currículo das escolas estaduais.

Este primeiro momento, que durou três dias, contabilizou 24 horas na carga horária de formação dos formadores, os PCNPs de ciências que participaram do Seminário de Serra Negra e que foram os tutores do curso 2. As demais 36 horas deste curso para os formadores foram divididas em $28 \mathrm{~h}$ na etapa à distância, via plataforma EFAP e 8h num outro Seminário Centralizado que ocorreu em Águas de Lindóia de 09 a 11 de dezembro de 2013. Embora tenha ocorrido em três dias de muita atividade, podendo contabilizar 24 horas, apenas 8 horas entraram na totalidade das horas exigidas para a conclusão do curso 1.

Após o encontro de Serra Negra, os PCNP realizaram atividades na plataforma da EFAP. Depois disso passaram a atuar como formadores do curso 2, que será abordado a seguir. Ainda como formadores do curso 2 participaram de Seminário Centralizado em Águas de Lindóia, de 09 a 11 de dezembro. Nesta ocasião, os professores de ciências, cujas situações de aprendizagem foram selecionadas nos seminários descentralizados das Diretorias de Ensino, apresentaram as situações para toda a rede. Esta apresentação contou para a certificaçáo como formadores dos PCNP e também para os próprios professores que as apresentaram como atividades certificadas.

\section{Curso 2- Formação de professores de ciências}

Os professores que participaram deste curso 2 foram inscritos por suas Diretorias de Ensino. Isso foi diferente do que aconteceu com os professores de Língua Portuguesa e Matemática; sendo o professor habilitado e tendo aulas atribuídas, já ocorria sua inscrição automaticamente.

Com relação aos professores de ciências que atuam nas escolas da Diretoria de Ensino Leste 1 (Leste 1) os números de inscritos são: 198, dos quais 152 confirmaram a inscrição. Destes, 132 concluíram o curso.

A Etapa 1, com o Encontro Presencial em que foram trabalhadas as oficinas de formação, aconteceu na Leste 1, de 27 a 30 de agosto e de 9 a 10 de setembro de 2013. Segundo o calendário do curso para todo o estado a tal etapa deveria ocorrer entre 26 de agosto a 28 de setembro de 2013, de acordo com a organização das Diretorias.

Em $24 \mathrm{~h}$ de formação, os professores tiveram contato com a proposta, as concepçóes, situações de aprendizagem, metodologias de ensino, elaboraram situações de aprendizagem em grupo, que foram poste- 
riormente, na plataforma digital, retrabalhadas para serem apresentadas. No encontro presencial puderam trocar experiências entre seus pares e para construírem juntos uma SA com base na realidade da sua escola e dos conhecimentos de seus alunos. A orientação era para que colocassem o elaborado em prática, aplicando a SA com seus alunos, para no seminário descentralizado apresentarem os resultados aos seus colegas. Imbernón (2011, p. 82), afirma que:

Quando os professores trabalham juntos, cada um pode aprender com o outro. Isso os leva a compartilhar evidências e informação e a buscar soluçóes. A partir daqui os problemas importantes das escolas começam a ser enfrentados com a colaboração entre todos, aumentando as expectativas que favorecem os estudantes e permitindo que os professores reflitam sozinhos ou com os colegas sobre os problemas que os afetam.

Para que os professores compreendessem como foi estruturado o caderno do aluno e como as situaçóes de aprendizagem presentes nestes cadernos estáo dispostas, utilizaram como exemplo a SA- O Ciclo Hidrológico e o uso da água pelo ser Humano - 5a série $1^{\circ}$ Bimestre, contendo uma síntese descrita num quadro específico com o conteúdo e tema a serem trabalhadas, as competências e habilidades que os alunos precisam aprender as estratégias de ensino que o professor deve adotar, recursos utilizados pelo professor e pelo aluno e pôr fim a avaliação. Esta foi selecionada por conter bem definidas as etapas de construçáo da aprendizagem dos alunos.

Toda SA inicia com um quadro explicativo em que consta o tempo previsto, o conteúdo e tema abordado, as competências e habilidades que serão trabalhadas dentro da SA, as estratégias de ensino que o professor poderá ou "deverá" utilizar, os recursos necessários para a experimentação, e por final uma avaliação.

A segunda etapa, a distância, foi de 31 de agosto a 29 de setembro de 2013, contabilizando $28 \mathrm{~h}$ de curso. Este momento do curso deu-se por meio da plataforma AVA-EFAP, em que os professores realizavam as leituras, participavam de fóruns e realizavam atividades individuais. Foi utilizada também a ferramenta blog para produzir, divulgar e compartilhar o conhecimento, utilizando assim as Tecnologias Digitais de Informação e Comunicação (TDIC). A SA que os professores iniciaram a elaboração no encontro presencial, foi aprimorada por um grupo de professores, que foram selecionados para discutir, apurar e organizar passo a passo de forma a praticar a escrita colaborativa, promovendo assim a reflexão sobre a linguagem cientifica como parte da construção da realidade de cada escola, ressaltando a relação do Currículo com as atividades de leitura e escrita em aulas de Ciências.

Segundo DAY (2001), o modo que o currículo é interpretado depende da construçáo das identidades pessoais e profissionais dos professores. Neste sentido, o conhecimento do conteúdo e o conhecimento pedagógico não podem estar divorciados das necessidades pessoais e profissionais dos professores (DAY, 2001 p. 17).

Os professores não podem ser formados (passivamente). Eles formam-se (activamente). É, portanto que participem activamente na tomada de decisóes sobre o sentido e os processos da sua própria aprendizagem. O êxito do desenvolvimento 
da escola depende do desenvolvimento do professor. Planificar e apoiar o desenvolvimento profissional ao longo de toda a carreira é uma responsabilidade conjunta dos professores, das escolas e do Governo.

$\mathrm{Na}$ etapa 3, o seminário descentralizado, que na Leste 1 aconteceu dia 03 de dezembro de 2013, os professores apresentaram as situaçóes de aprendizagem construídas, o que contabilizou $8 \mathrm{~h}$ no curso. Foi escolhido um professor por escola.

\section{Curso 3: Aprofundamento de Conteúdos e Metodologias}

O curso 3 foi todo a distância, para os inscritos no curso 2 e que confirmassem a inscrição no curso 3. Teve um total de $80 \mathrm{~h}$. Seu conteúdo foi conceitual, sem o trabalho com metodologias de ensino a serem elaboradas na ocasião do curso.

\section{Os professores participantes}

Buscando captar e entender se a participação no curso MGME-Ciências, da perspectiva dos professores, impactou em sua prática profissional, procedeu-se a pesquisa empírica com dois professores ex-cursistas. Estes professores lecionam Ciências em uma escola de ensino integral pertencente à Leste 1. Foram utilizados como procedimentos de pesquisa o questionário e a entrevista semiestruturada. Com o questionário buscou-se traçar o perfil dos professores participantes e elencar sua visão sobre sua situação funcional e formação de modo a relacionar os elementos daí advindos com as colocaçóes da entrevista.

\section{0 questionário}

Tem-se uma amostra composta por uma mulher e um homem, com idades que variam de 51 a 54 anos. Os dois entrevistados são casados, sua composição familiar sofre uma pequena variação entre um e dois filhos e nenhum possuem cônjuges na profissão de professor. A formação dos cônjuges dos dois entrevistados é de ensino médio técnico, sendo um já aposentado e o outro ainda trabalhando. Seus pais têm uma variação entre o ensino fundamental incompleto a ensino técnico profissionalizante, suas mães possuem ensino fundamental incompleto e nunca trabalharam. Possuem uma renda familiar em torno de 10 a 15 salários mínimos. Todos possuem residência própria e nas horas livres gostam de ler e passear com sua família.

Os professores possuem uma formação básica em escolas públicas e particulares, a formação acadêmica se deu em Universidades particulares nos anos 80. Os dois fizeram o curso de Ciências, com módulo presencial. Verifica-se que a professora possui três pós-graduaçôes tanto na área da educação como na biológica. $\mathrm{O}$ professor também possui pós-graduação na área da educaçáo. Apresentam vários cursos de aperfeiçoamento todos eles oferecidos pela SEESP com duração de 30 a 80 horas, e ainda relataram que estão realizando um curso de aperfeiçoamento em Ensino Integral. 
Os dois professores em questão possuem carga máxima, ou seja, 40 horas semanais, sendo que um deles tem dois cargos na rede, um efetivo e o outro OFA por este motivo possuem uma carga horária de 60 horas semanais. Nenhum deles tem carga suplementar. $\mathrm{Na}$ unidade escolar que atuam hoje, possuem de 5 meses a 2 anos de trabalho, não podemos esquecer que são professores designados (Escola de Ensino Integral). Os dois lecionam Matemática e Ciências. São professores experientes, com uma variação de 22 anos a 27 anos dentro a carreira do magistério público. Os dois alegam que gostam muito do que fazem, porém verificamos uma angustia em relação à baixa remuneração atual, planejam suas aulas diariamente.

Seguindo o estudo das fases da carreira docente de Huberman (1992 p.42), os dois professores estáo na fase de motivação de suas carreiras. Nesta fase seriam, assim, os mais motivados, os mais dinâmicos, os mais empenhados nas equipas pedagógicas ou nas comissóes de reforma que surgem em várias escolas. Por ser a fase mais longa, Huberman destaca que o professores podem ser classificados em três tipos: (1) Professores que investem no seu desenvolvimento profissional e buscam diversificar suas metodologias e estratégias a fim de aprimorar seu trabalho, para tanto se especializam em cursos de formação continuada; (2) Professores que se identificam com a área administrativa, e (3) Professores que não se adaptaram e vão diminuindo o número de aulas, muitas vezes, abandonas a profissão ou, por possuírem uma estabilidade profissional, mantêm o mínimo de aulas e exercem outra profissão paralelamente.

Os dois professores que participaram desta pesquisa ainda se encontram nesta fase de motivação, pois continuam arduamente realizando cursos de formação continuada e a procura de novas posiçôes dentro da carreira. Verificam-se quando os mesmos se candidataram a trabalhar no Programa de Ensino Integral.

\section{A entrevista}

As entrevistas foram previamente agendadas, sendo que cada uma foi realizada em dias diferentes e o processo ocorreu dentro da unidade escolar. As entrevistas foram semiestruturadas. O pesquisador chegou às entrevistas com um roteiro prévio de perguntas com as quais procuraria chegar às respostas relacionadas ao problema da pesquisa. Foi categorizada em: Visão do Professor, Formação continuada, Currículo Oficial do Estado de São Paulo e Apropriação do Curso Melhor, Gestão Melhor Ensino - Formação de Professores de Ciências.

\section{Categoria 1- Visão do professor}

Compuseram esta categoria 10 questôes sobre: como o professor vê seu trabalho, desafios da docência, o trabalho na escola de ensino integral, posiçâo quanto à disciplina que ministra, planejamento das aulas, relacionamento com os alunos, participação dos mesmos nas atividades e apreensôes de percepçôes dos discentes quanto às aulas. Dentre as questôes feitas selecionou-se a que segue. Cabe ressaltar que para cada categoria faz parte da analise deste artigo apenas uma questão da entrevista, com exceção da categoria 4. 


\section{Quadro 1 - Como você vê o seu trabalho em frente às dificuldades?}

P1. Olha. Todos os dias eu vejo o meu trabalho como um desafio, porque as crianças não são iguais, as salas são heterogêneas, então, eu encaro meu trabalho como um desafio, a ser transposto a cada aula, não e nem a cada dia, e a cada aula, assim a escola tem muitas realidades diferentes, entáo eu encaro dessa maneira.

P2. As dificuldades em que sentido? As dificuldades em sala de aula como professor um dos grandes motivadores e o desinteresse que os alunos, enquanto prestar atenção, se concentrar haja vista que a minha disciplina ela requer uma concentração pro aluno poder entender toda aquela sequência é o que falta isto é também a falta de maturidade dos alunos isso pra ser ensino fundamental ainda são muitos imaturos.

Fonte: dados da pesquisa.

\section{Categoria 2- Formação Continuada (FC)}

Para esta categoria 12 questóes fizeram parte da entrevista. Perguntou-se sobre: conceito de FC, participação em cursos de contribuições para a prática docente, práticas da SEESP que consideram FC (orientaçôes técnicas, por exemplo), entendimento da posiçâo da SEESP quanto a FC, início de freqüênciaem FC e comentários sobre.

\section{Quadro 2 - Que contribuições que a formação continuada trouxe para sua prática educacional?}

P.1. Olha um dos últimos cursos que eu fiz que fosse o MGME, me deu assim outra visão das sequências didáticas, entendeu, porque a gente lá foi muita a troca, então eu planejava de um jeito uma colega via de outro jeito aí nós trocávamos muita informação, né então as situações de aprendizagem as sequências eu passei a ministrar de outra maneira porque eu tenho uma visão e o colega tem outra então, Poxa olha daquele jeito é mais legal vou aplicar, por exemplo, esse curso MGME foi fantástico porque foi uma troca foi uma troca importante na minha concepção de ministrar aula de sala de aula essa troca entre os pares entre os professores da própria área uma troca de experiência.

P.2. Eu acho que, com relação a esses cursos ai, ela traz muito assim a vivência de cada um e as novas situaçóes que são abordadas que nós devemos abordar em sala de aula, onde abre um leque para nos porque às vezes você fica achando que a sua aula ela está de acordo com aquilo, de acordo com o que você acha de acordo com a sua concepção, quando você vai para uma orientação técnica uma formação ai, ai você verifica com seus pares as experiências deles e ai você fala poxa vida porque eu não utilizo isso e ai você passa a utilizar também uma troca de experiências.

Fonte: dados da pesquisa.

\section{Categoria 3- Currículo Oficial do Estado de São Paulo}

Compuseram esta categoria 17 questóes. Entre elas: o que é currículo em sua opinião, conhecimento sobre o currículo oficial do estado para a área e posiçáo sobre, ocorrência de orientaçóes para desenvolver o 
currículo, uso de material de apoio para desenvolvê-lo, dificuldades em lidar com ele, trabalho com SAs e estratégias de avaliação e de recuperação contínua.

Quadro 3 - Qual o seu posicionamento em relação ao currículo oficial da SEE/SP da disciplina de Ciências?

P.1. O currículo eu acho ele muito bom, mas em alguns aspectos eu achei um pouquinho difícil. Porque o aluno deveria trazer um conhecimento muito profundo e às vezes ele não tem entáo claro que o currículo você não pode seguir só o que está ali você tem que complementar eu no meu caso eu trago textos pra complementar pra fazer uma leitura trago exercícios um complemento ele poderia ser um pouquinho mais completo e menos difícil só isso que eu acho.

P.2. Então, do currículo em si ele é bom, bom. Por que, Olha! Nós temos aí, a minha disciplina mesmo, ela a todo o momento, ela está vivendo um constante processo aí né e às vezes determinados itens tópicos eles tão pouco defasados e nós temos que correr atrás do que aconteceu porque nós temos casos que acontecem né, quase todo o dia, e o currículo em si, ele aborda, mas o que ficou às vezes lá pra atrás, ai nós corremos atrás disso pra ficarmos interados porque senão o aluno ele percebe que você não está acompanhando lá no seu dia a dia, pelo uso da internet que ele tem, ele faz algumas perguntas do que aconteceu ontem na parte medicina da evolução e ai que está acontecendo e a gente tem que correr atrás.

Fonte: dados da pesquisa.

\section{Categoria 4- Curso Melhor Gestão, Melhor Ensino - Formação de professores de Ciências.}

Integraram esta categoria 11 questóes sobre: contribuição do curso para docência, utilização do aprendido, importância da troca de experiência entre os cursistas, utilização de TICs e percepção sobre participação nos seminários descentralizados e centralizados.Destas 11, 5 estão aqui transcritas.

\section{Quadro 5 - Quais as contribuições do curso MGME- Formaç̧ão de Professores de Ciências para sua profissão?}

P.1. É, foi à apropriação de novas metodologias para trabalharmos em sala de aula, a troca de experiência entre professores né, sobre a mesma sequência didática foi muito rica.

P.2. Bom para minha profissão às contribuiçôes, elas foram bem, bem grandes né, no que diz respeito aos conteúdos que, os professores trabalhava em sala de aula, e com o aprimoramento do nosso trabalho em sala de aula, procurando diversificar, sair às vezes um pouquinho daquela, do caderno do aluno que nós temos né, para situaçóes novas e diversificadas, para ampliar as inúmeras situaçōes que nós temos em sala de aula, com situaçôes de aprendizagem né, dos conteúdos em geral, abrir um leque um, um leque muito grande.

Fonte: dados da pesquisa. 


\section{Quadro 6 - De que maneira você utiliza o conhecimento adquirido no Curso - MGME Formaç̧ão}

\section{de Professores de Ciências?}

P.1. Aí, eu procuro aplicar todas as maneiras, todas às estratégias que nós adquirimos durante o curso no decorrer do curso, eu procuro aplicá-las todas em sala de aula.

P.2. Então com relação aos conhecimentos adquiridos no curso nós podemos ter, aí, algumas metodologias para nós usarmos em sala de aula, que até então eu mesmo não, eu utilizava com uma certa frequência e aí de acordo com as orientaçóes que nos foram dadas né, um determinado assunto, você poderia abordar é, numa, vamos supor como se fosse como se fala, Mapa conceitual né foi um dos itens que foi trabalhado isso facilita muito em sala de aula né isso daí eu mesmo não trabalha isso em sala de aula e depois eu dessas orientaçôes do curso eu comecei a trabalhar facilitou bastante.

Fonte: dados da pesquisa.

\section{Quadro 7 - Que conhecimentos você adquiriu para sua pratica diária?}

P.1. Esse curso me ajudou a diversificar as estratégias usadas em sala de aula, tirar sair daquela lousa e giz, fazer mais uso da tecnologia, da leitura dos mapas conceituais, uso de imagens e uma diversidade de estratégias muito grande.

P.2. No curso aconteceu, Aconteceu e muito nós trocávamos muitas informações, com em relação, a isso experiências vivenciadas em sala de aula mesmo, das dificuldades que nós professores tínhamos e temos ainda em sala de aula, essa troca ela é muito, ela foi muito boa, não o blog, blog foi fundamental porque eu acho que se nós não tivéssemos esse blog ficaria difícil né, articulação, é assim por todo o grupo, é que nós temos um grupo grande então à troca de experiência através do blog a experiência foi muito salutar, muito boa mesmo.

Fonte: dados da pesquisa.

\section{Quadro 8 - Qual trabalho você apresentou no Seminário Descentralizado. Descreva-o:}

P.1. Eu cheguei à sala de aula com uma situação-problema, cheguei com um celular uma folha de papel sulfite uma folha de papel celofane e uma latinha de alumínio e aí eu coloquei uma proposta para os alunos, nós deveríamos envolver um celular nos três materiais. E aí fazer as chamadas e o que eles deveriam me responder, porque quando os celulares eram envolvidos folha de sulfite, papel celofane as chamadas eram completadas, e quando eu colocava dentro da latinha, não havia sinal algum, gerou lá, uma polêmica, uma discussão muito rica, porque eles deram muitas ideias né, e aí eles sabiam que alguma coisa bloqueava as ondas eletromagnéticas, mais aí eles não sabiam explicar corretamente como que era. E aí para fechar atividade eu expliquei que era pra fazer gaiola de Faraday. 
Quadro 9 - Como você se sentiu ao participar dos Seminários de Boas Práticas organizados pela Secretaria Estadual de Educação do Estado de São Paulo?

P.1. Muito feliz né, é muita responsabilidade, porque no meio de quase 90 escolas, o meu trabalho e de mais duas amigas foram selecionados então uma responsabilidade muito grande, mas muito feliz mesmo, eu fiquei e minhas amigas por conta da representação foram muito legal, muito bacana mesmo.

P.2. Depois de um curso, ah esclarece, muitas coisas pra nós entendeu, ele acaba assim abrindo, abrindo um pouco a sua cabeça, porque às vezes nós quando estamos em sala de aula, naquele seu mundo, ali com os alunos, e você, e você acha que você está fazendo seu serviço certinho né, mas, aí quando você participar de um curso né, desses seminários, aí você retoma toda a sua metodologia,

e você acaba o que, é mudando um pouquinho o seu trajeto né, porque às vezes nós, quando preparamos uma aula às vezes a gente prepara a aula para nós e não para o aluno. Então, nós temos que parar com isso, nós temos que preparar a nossa aula para o nosso aluno, para que o aluno entende daquilo que você fala, para a realidade do aluno e não para nossa realidade, porque nós estamos procurando algumas expectativas no aluno, e aí, a gente acaba ficando frustrado, porque são os nossos anseios, são as nossas expectativas, é errado porque, o interesse ir nas expectativas dos alunos né, buscar o que o aluno sabe. Essas experiências, sim porque além de, do compartilhamento, tudo, você tem toda a experiência de outros profissionais que estão, alguns mais tempo do que eu na rede e outros menos, mas o fator, tempo na rede às vezes, ele não é tudo pra indicar se o profissional se o professor, o profissional ele é bom ele é competente ou não é mas essa troca entre nós professores ela é muito boa, porque são vivências realizadas em sala de aula.

Fonte: dados da pesquisa.

\section{Considerações finais}

O que se esperava deste curso está dito por ele mesmo: esperava-se que os professores cursistas se apropriassem de sua base teórica e conceitual, bem como das metodologias de ensino propostas e que fossem condizentes com as diretrizes do currículo do estado, para que pudessem, entáo, replicar a metodologia de ensino com os alunos, de modo a participarem com mais eficácia da efetivação do objetivo de melhoria dos níveis de desempenho nas avaliaçôes sistêmicas como o Saresp, Saeb e Pisa.

O lugar da autonomia do professor em meio a essa estrutura está para ser discutido exaustivamente. $́$ É uma discussão longe de ser encerrada ou sobre a qual se chegou a um consenso.

Neste estudo, o que se quis saber é que valor e importância os professores participantes desta pesquisa atribuíram à sua participação no MGME, à sua formação profissional, e a relação desses elementos com sua atuaçáo profissional numa secretaria de estado de educaçáo com uma proposta curricular definida.

Nos relatos dos professores, a falta da tecnologia, na maioria das escolas, dificulta o desenvolvimento das atividades abordadas no curso. 
O curso ofereceu uma predisposiçấo para a troca de experiências entre os professores da mesma disciplina e até da mesma escola, em construir aulas, sequências didáticas, situaçôes de aprendizagem com o uso de metodologias diversificadas e o uso das tecnologias.

O que ocorre muitas vezes nos cursos de aperfeiçoamento é a fragmentação dos saberes sobre a educação e sobre os conceitos, onde se reflete sobre o que se vai fazer ou o que se deve fazer, sem a reflexão sobre o que se faz no "chão da sala de aula".

A reflexão sobre a prática, ao ser exercitada, pressupóe o crescimento profissional a partir do relato de experiências que devem estimular e corroborar com a capacidade do professor de ousar, modificar sua prática, muitas vezes sufocada pela cotidianidade alienante.

Trazer tal entendimento e tal percepçâo dos professores à tona por meio das entrevistas, ensaiando os retratos dos professores, tem por objetivo trazer os professores para a vanguarda de sua própria atuação e formação profissional.

O Curso Melhor Gestão, Melhor Ensino faz parte do programa de formação continuada e consiste em prover a garantia do direito aos professores. Esse aspecto se configura como dever do Estado em garantir condiçóes dignas para o desenvolvimento de um trabalho educativo que promova a qualidade das aulas ministradas na rede pública estadual.

Este texto procurou jogar luz sobre os professores que fizeram o curso. Analisou-se como, considerando todos os elementos referidos, perceberam o curso, como perceberam o impacto do curso em sua atuaçáo e desenvolvimento profissional. Procurou-se dar voz ao professor, o que, segundo Giroux (1999), é um dos mecanismos efetivos para propiciar transformações na educação em prol da constituição de uma escola e de uma sociedade mais democrática e igualitária.

\section{Referências}

BIOTO-CAVALCANTI, Patrícia Ap. Um currículo para a Formação dos professores da Rede Estadual Paulista. In: SALA, Eliana; BOCCIA, Margarete; BIOTO- CAVALCANTI, Patrícia Ap. (orgs.). Formaçáo de Professores. Contextos, Epistemologias e Metodologias. São Paulo: Big Time Editora, 2015. p. 15-56.

DAY, Christopher. Desenvolvimento Profissional de Professores. Os desafios da aprendizagem permanente. Portugal: Porto Editora, 2001.

GIROUX, Henry. Cruzando as fronteiras do discurso educacional: novas políticas em educação. trad. Magda França Lopes. Porto Alegre: Artes Médicas Sul, 1999.

HUBERMAN, M. O ciclo de vida professional de professores. In: NÓVOA, A. (org.). Vida de professores. Portugal: Porto Editora. 1992.

IMBERNÓN, Francisco. Formação Docente e Profissional: formar-se para a mudança e a incerteza. 9. ed. São Paulo: Cortez Editora, 2011. 
SÃO PAULO (Estado). Secretaria de Estado da Educação. Resoluçáo SE no 22, de 18 de abril de 2013 Institui o Programa "Melhor Gestão, Melhor Ensino", no âmbito da Secretaria da Educação. Disponível em: <http://www.rededosaber.sp.gov.br/portais/Portals/131/Resolu\%C3\%A7\%C3\%A3o\%20SE-22\%20 de\%2018-42013\%20Programa\%20Melhor\%20Gest\%C3\%A3o.pdf>. Acesso em: jun. 2014. 